\title{
Novel type of peritoneocentesis trocar-assisted distal ventriculoperitoneal shunt placement with supervision via a one-port laparoscope
}

\author{
GUANGMING WANG, JINLU YU, YONGXIN LUAN, YANWU HAN and SHUANGLIN FU \\ Department of Neurosurgery, First Hospital of Jilin University, Changchun, Jilin 130021, P.R. China
}

Received March 2, 2016; Accepted March 23, 2017

DOI: $10.3892 /$ etm.2017.4926

\begin{abstract}
Ventriculoperitoneal shunts (VPS) are the primary treatment for hydrocephalus and are associated with a high risk of complications, specifically in patients who are obese or have abdominal adhesions or shunt revisions. The present study describes the use of a novel type of peritoneal catheter peritoneocentesis trocar insertion with the assistance of a one-port laparoscope. A total of 36 patients with hydrocephalus underwent this novel type of peritoneocentesis trocar-assisted VPS. The distal shunt catheter was placed into the right subdiaphragmatic space and the catheter was traversed through a single hole drilled through the liver falciform ligament. The duration of the laparoscopic surgery ranged from 6-18 min (mean 10.4 $\pm 1.6 \mathrm{~min}$ ). No shunt-related infections or catheter malfunctions or injuries to the intra-abdominal organs occurred. The total abdominal incision length was $1.0 \mathrm{~cm}$ $(0.5+0.5 \mathrm{~cm})$. No laparoscopy-related complications were observed during follow-up assessments. The novel approach used in the current study is very easy to perform, and this method may significantly reduce the risk of malfunction complications. The presented method also has the advantages of reduced trauma and a simpler surgery. The current study indicated that this simple, minimally invasive procedure was beneficial for patients with hydrocephalus, specifically in cases of patients with obesity, peritoneal adhesions or shunt revisions.
\end{abstract}

\section{Introduction}

Hydrocephalus is a common brain condition that is treated with neurosurgery. The diversion of the cerebrospinal fluid to relieve hydrocephalus may be accomplished via a number of different methods $(1,2)$. The most commonly used method is the

Correspondence to: Dr Shuanglin Fu, Department of Neurosurgery, First Hospital of Jilin University, 71 Xinmin Avenue, Changchun, Jilin 130021, P.R. China

E-mail: itisslfu@163.com

Key words: hydrocephalus, ventriculoperitoneal shunt, peritoneocentesis trocar, laparoscope ventriculoperitoneal shunt (VPS) $(3,4)$. Complications occur following VPS placement in 5-47\% of cases. The majority of these complications involve the peritoneal catheter $(5,6)$. A number of techniques are used to place the distal end of the shunt into the peritoneal cavity, including the following: i) Exposing various layers of the abdomen, ii) placing a trocar into the peritoneum via a mini-laparotomy followed by placement of the distal end into the peritoneum and iii) laparoscopy (7). However, these methods may lead to a number of different complications, including trauma, infection and malfunctions of the distal section of the shunt. Since the 1960s, a number of shunts have been developed, and each novel design has been more sophisticated and expensive than its predecessor (8), but only marginal improvements in efficacy have been achieved. An increasing number of surgeons have come to hypothesize that the falciform ligament may be used as a natural fixation point on which to secure the catheter.

The present study describes experience with the use of a peritoneocentesis trocar and laparoscopy-guided insertion of the distal catheter, which significantly decreased the number of complications and advantageously reduced trauma and facilitated a simple surgery, particularly in patients with previous abdominal operations, shunt revisions or obesity.

\section{Patients and methods}

Patients. The present study was completed between January 2010 and December 2015 and included 36 patients (24 men and 12 women). The patients ranged in age from 19 to 62 years $(42.94 \pm 13.99$ years; $66.7 \pm 21.6 \mathrm{~kg})$. All patients who underwent VPS procedures at the First Hospital of Jilin University (Jilin, China) between January 2010 and December 2015 were included in the analysis. The aim of the current study was to evaluate the abdominal section of the procedure; patients who underwent distal revisions were also enrolled (Table I). Data were retrospectively collected from patients' medical files, surgical reports and follow-up notes. Written informed consent was obtained for all aspects of the treatment from all patients or their relatives. The study protocol was approved by the institutional review boards of The First Hospital of Jilin University.

Peritoneocentesis trocar. As in a previous study (9), the peritoneal trocar was composed of different parts, including 
the sheath and core needle, made of steel. The trocar was $\sim 13 \mathrm{~cm}$ long with an outer sheath diameter of $0.5 \mathrm{~cm}$ and an inner needle diameter of $\sim 0.3 \mathrm{~cm}$. The sheath consisted of a semi-opened form with a $0.3-\mathrm{cm}$ width striped gap in the lateral wall along its length (Fig. 1).

Surgical procedure. Surgical procedures for the novel shunt and shunt revision groups were performed under general anesthesia (propofol; 4-12 mg/kg/h intravenously; AstraZeneca, Cambridge, UK). In the novel shunt group $(n=27)$, the placement of the peritoneal catheter was only performed following the successful insertion of the ventricular catheter and fixation of the diversion drainage pump. Next, the distal shunt tube was gradually inserted through the subcutaneous tissue of the anterior aspect of the neck, chest and xiphoid process (Fig. 2A). In the shunt revision group $(n=9)$, an incision was made on the surface of the dysfunctional catheter near the subxiphoid area and then a new catheter was used, rather than the old one.

Pneumoperitoneum was created using a closed technique with a Veress needle. Carbon dioxide was insufflated to a pressure of $12 \mathrm{mmHg}$. A $0.5-\mathrm{cm}$ umbilical trocar was inserted (Fig. 2B), and a $0.5-\mathrm{cm}$ videoscope was used. Under videoscopic guidance, the novel type of peritoneocentesis trocar was inserted into the subxiphoid area of the abdomen via the $0.5-\mathrm{cm}$ skin incision with the distal shunt. Once the trocar had punctured the peritoneum, the trocar was drilled into the falciform ligament of the liver, and the needle core was removed. The shunt catheter was subsequently inserted into the peritoneal cavity through the hard channel of the introducer sheath. The catheter length remaining within the peritoneal was $20-25 \mathrm{~cm}$. The sheath was removed (Fig. 3). The patency of the catheter was ensured via laparoscopic supervision. Following this, the laparoscope was removed and the skin incisions were closed.

\section{Illustrative cases}

Case 10. A 19-year-old male patient was admitted in May 2012 to the First Hospital of Jilin University due to redness, swelling and purulent exudation at the abdominal end of the shunt tube. These symptoms had been present for 1 week and began 5 years after the VPS surgery. The patient underwent VPS surgery at the First Hospital of Jilin University 5 years previously and had recovered and was discharged after 7 days. The patient was admitted to hospital 1 week prior to surgery due to redness and swelling accompanied by purulent exudation at the abdominal incision without a clear cause. The protruding shunt tube was visible in the patient's abdomen accompanied by a large amount of empyema (Fig. 4). A physical examination was conducted and the patient was clear in consciousness, with no positive signs of the nervous system. The patient's body mass index (BMI) was 32, with a flat and soft abdomen with a thick abdominal fat pad. The patient's abdomen was not tender to the touch and although he did not experience rebound tenderness, the patient did exhibit borborygmus. Therefore, the patient underwent emergency laparoscopy-assisted VPS surgery under general anesthesia as described above. A $0.5-\mathrm{cm}$ incision was made at the location of the shunt tube $2-\mathrm{cm}$ below the xiphoid process. The shunt tube was exposed and cut. The proximal end of the shunt tube was removed from the occipital area, and a new abdominal-end tube was placed within the original subcutaneous tunnel. Pneumoperitoneum was established using $\mathrm{CO}_{2}$ at a pressure of $1.07-1.33 \mathrm{kPa}$. Following this, a $0.5-\mathrm{cm}$ umbilical incision was made and the laparoscopic lens was introduced. Under laparoscopic monitoring, the novel type of abdominal puncture needle was used to pierce the falciform ligament, and the shunt tube was introduced into the hole of the falciform ligament along the hard channel of the abdominal trocar. The abdomen puncture needle was withdrawn when $\sim 20 \mathrm{~cm}$ of the laparoscopy was indwelled within the abdominal cavity. The shunt pump was pressed under laparoscopic monitoring to confirm that the VPS tube was functioning. The abdominal incision was subsequently sutured and the distal end was removed from the ruptured area of the lower abdomen. Open drainage was utilized. The patient recovered and was discharged 3 weeks after surgery. The patient was assessed every 6 months for 36 months, during which time the VPS tube functioned well as assessed via through computed tomography (CT) scanning and pressure of the drainage pump.

Case 30. A 60-year-old male patient was admitted in December 2011 to The First Hospital of Jilin University due to an unsteady gait (present for 15 days) and confusion (7 days). The patient had been administered with antibiotics $(2.0 \mathrm{~g}$ cefmenoxime daily) due to bacterial meningitis 25 years previously. When the patient had become stable, traffic hydrocephalus developed; therefore, he underwent right VPS surgery. The patient recovered well following surgery. Replacement of the abdominal end of the VPS tube had been performed due to shunt tube occlusion 1 year previously. A new abdominal-end shunt tube was placed in the patient's left lower abdomen during surgery, and he recovered well. However, 15 days prior to admission to The First Hospital of Jilin University, the patient developed double vision accompanied by an unstable gait and a progressive decline in cognitive ability. He also developed confusion 7 days prior to admission. Head computer tomography (CT) and magnetic resonance imaging (MRI) scans revealed hydrocephalus. Subsequently, the patient was transferred to The First Hospital of Jilin University by his relatives. Following a head CT and a detailed physical examination, the patient was admitted with a diagnosis of hydrocephalus. The patient's general condition was poor during admittance. A physical examination revealed confusion. The patient was able to answer questions but was not fluent and was able to follow the doctor's advice at times. The pupils were the same size (circular with diameters of $\sim 3.0 \mathrm{~mm}$ ) and exhibited the light reflex. He was able to move his limbs well and was negative for bilateral Babinski signs. The balloon of the shunt pump in the right occipital area was difficult to press and bounce. An auxiliary examination with multiple-level craniocerebral MRI scanning revealed varying degrees of expansion within the ventricle system, including the lateral ventricles, third ventricle and fourth ventricle. As such, the patient was diagnosed with traffic hydrocephalus.

The patient underwent replacement of the VPS tube assisted by laparoscopy under general anesthesia as described above. A $0.5 \mathrm{~cm}$ incision was made at the location of the shunt tube ( $2 \mathrm{~cm}$ below the xiphoid process). The original abdominal end of the shunt tube was removed, and the new abdominal-end tube was placed along the original subcutaneous tunnel. Pneumoperitoneum was established using $\mathrm{CO}_{2}$ 
Table I. Patient demographics.

\begin{tabular}{|c|c|c|c|c|c|c|}
\hline Patient & Sex & Age & Abdominal condition & Etiology & Diagnosis & Surgery \\
\hline 1 & Male & 30 & Distal dysfunction & Trauma & Communicating & Revision \\
\hline 2 & Male & 43 & Distal dysfunction & Trauma & Communicating & Revision \\
\hline 3 & Male & 57 & Normal & sSAH & Communicating & New \\
\hline 4 & Female & 56 & Normal & Trauma & Communicating & New \\
\hline 5 & Male & 51 & $\begin{array}{l}\text { Abdominal subcutaneous } \\
\text { fat pad (BMI } \geq 28)\end{array}$ & Trauma & Communicating & New \\
\hline 6 & Female & 24 & Normal & Trauma & Communicating & New \\
\hline 7 & Male & 27 & $\begin{array}{l}\text { Previous abdominal } \\
\text { operational history }\end{array}$ & Idiopathic & Normal pressure & New \\
\hline 8 & Male & 29 & Normal & Trauma & Communicating & New \\
\hline 9 & Female & 44 & Normal & Trauma & Communicating & New \\
\hline 10 & Male & 19 & $\begin{array}{l}\text { Abdominal subcutaneous } \\
\text { fat pad (BMI } \geq 28)\end{array}$ & Idiopathic & Normal pressure & Revision \\
\hline 11 & Male & 27 & Normal & Idiopathic & Normal pressure & New \\
\hline 12 & Male & 50 & Distal dysfunction & Idiopathic & Normal pressure & Revision \\
\hline 13 & Male & 43 & Distal dysfunction & Brain hemorrhage & Communicating & Revision \\
\hline 14 & Female & 62 & Normal & Trauma & Communicating & New \\
\hline 15 & Female & 56 & $\begin{array}{l}\text { Previous abdominal } \\
\text { operational history }\end{array}$ & Idiopathic & Normal pressure & New \\
\hline 16 & Male & 30 & Normal & Trauma & Communicating & New \\
\hline 17 & Male & 54 & Normal & Trauma & Communicating & New \\
\hline 18 & Male & 53 & $\begin{array}{l}\text { Abdominal subcutaneous } \\
\text { fat pad }(\mathrm{BMI} \geq 28)\end{array}$ & Occupy lesion & Obstructive & New \\
\hline 19 & Female & 59 & Normal & Meningitis & Communicating & New \\
\hline 20 & Male & 60 & Normal & sSAH & Communicating & New \\
\hline 21 & Male & 35 & Normal & sSAH & Communicating & New \\
\hline 22 & Female & 62 & Normal & Idiopathic & Normal pressure & New \\
\hline 23 & Male & 27 & Distal dysfunction & Trauma & Communicating & Revision \\
\hline 24 & Female & 32 & Normal & Idiopathic & Normal pressure & New \\
\hline 25 & Male & 23 & Normal & Trauma & Communicating & New \\
\hline 26 & Male & 46 & $\begin{array}{l}\text { Abdominal subcutaneous } \\
\text { fat pad }(\mathrm{BMI} \geq 28)\end{array}$ & Trauma & Communicating & New \\
\hline 27 & Female & 43 & Distal dysfunction & Trauma & Communicating & Revision \\
\hline 28 & Female & 53 & Normal & Idiopathic & Normal pressure & New \\
\hline 29 & Male & 43 & $\begin{array}{l}\text { Previous abdominal } \\
\text { operational history }\end{array}$ & Trauma & Communicating & New \\
\hline 30 & Male & 60 & Distal dysfunction & Meningitis & Communicating & Revision \\
\hline 31 & Male & 21 & Normal & Trauma & Communicating & New \\
\hline 32 & Female & 60 & Peritonitis history & Trauma & Communicating & New \\
\hline 33 & Male & 28 & Normal & Trauma & Communicating & New \\
\hline 34 & Female & 57 & Distal dysfunction & Idiopathic & Normal pressure & Revise \\
\hline 35 & Male & 29 & Normal & Trauma & Communicating & New \\
\hline 36 & Male & 53 & $\begin{array}{l}\text { Abdominal subcutaneous } \\
\text { fat pad }(\mathrm{BMI} \geq 28)\end{array}$ & Trauma & Communicating & New \\
\hline
\end{tabular}

BMI, body mass index; sSAH, spontanous subarachnoid hemorrhage; new, patients with no history of treatment; revise, patients with an existing catheter that was replaced.

at a pressure of $1.07-1.33 \mathrm{kPa}$. A $0.5-\mathrm{cm}$ umbilical incision was made, and the laparoscopic lens was introduced. The VPS tube was covered with peritoneum and the greater omentum
(Fig. 5). The abdominal end of the new shunt tube was placed under laparoscopic monitoring. The patient recovered and was discharged 2 weeks after surgery; he was assessed every 

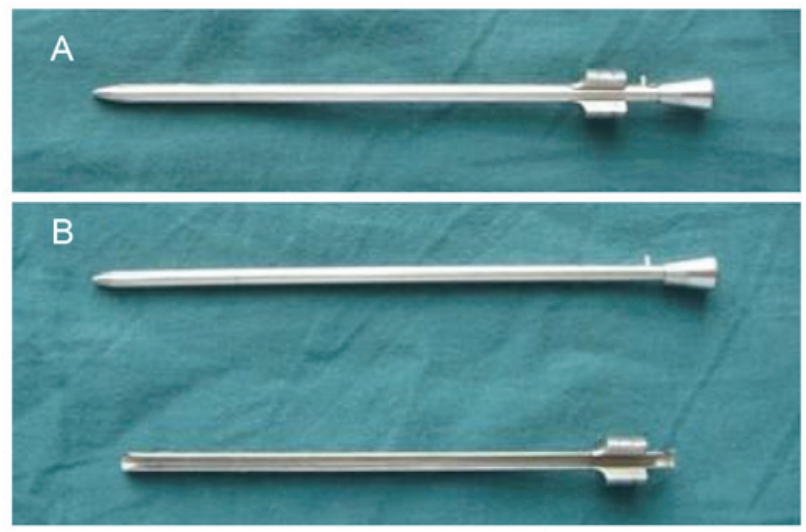

Figure 1. Peritoneal trocar. (A) Assembled for use and (B) separated to demonstrate the core and sheath.

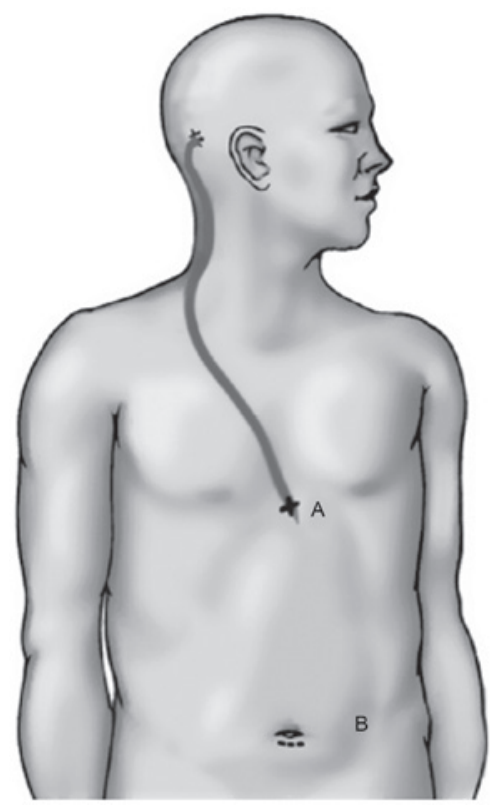

Figure 2. (A) Incision for the distal catheter (B) and the incision for the laparoscope.

6 months for 16 months following the procedure, during which time the VPS tube functioned well as assessed by physical examination, CT scanning, gait test and Mini-mental State Examination (MMSE).

\section{Results}

The duration of the entire VPS implantation ranged from 22 to $53 \mathrm{~min}$, and the average surgery time was $32.6 \pm 5.6 \mathrm{~min}$. Duration of laparoscopy ranged from 6 to 18 min (mean, $10.4 \pm 1.6 \mathrm{~min}$ ). Among the 36 patients who received new shunts, 19 exhibited no history of abdominal surgery, 3 patients had a previous history of abdominal surgery, 4 patients were obese (BMI $\geq 28$ ), and 1 patient had a history of peritonitis. Notably, 1 obese patient (BMI $\geq 28$ ) underwent abdominal shunt revision and 8 patients with distal dysfunction underwent shunt revision (Table I). Patients and their relatives were informed and provided consent for all aspects of treatment. The mean follow-up period was $18.11 \pm 9.29$ months. There were no

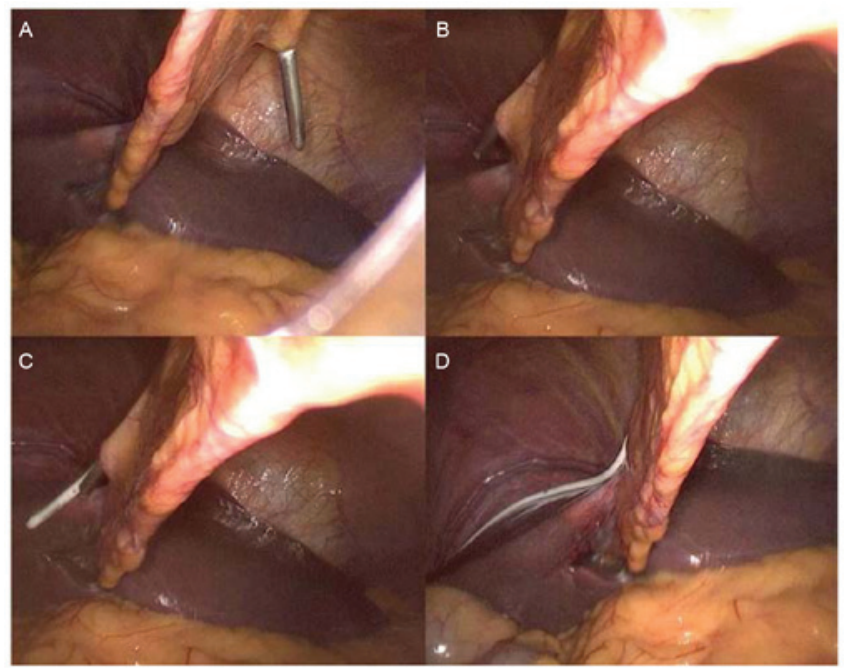

Figure 3. Placement of the distal catheter using a peritoneal trocar and a single-port laparoscope. (A) Puncture of the peritoneum with the trocar. (B) Drilling of the falciform ligament. (C) Removal of the trocar core and introduction of the distal catheter through the trocar. (D) Removal of the trocar sheath leaving the catheter within the peritoneal cavity. The shunt catheter passed through the falciform ligament.

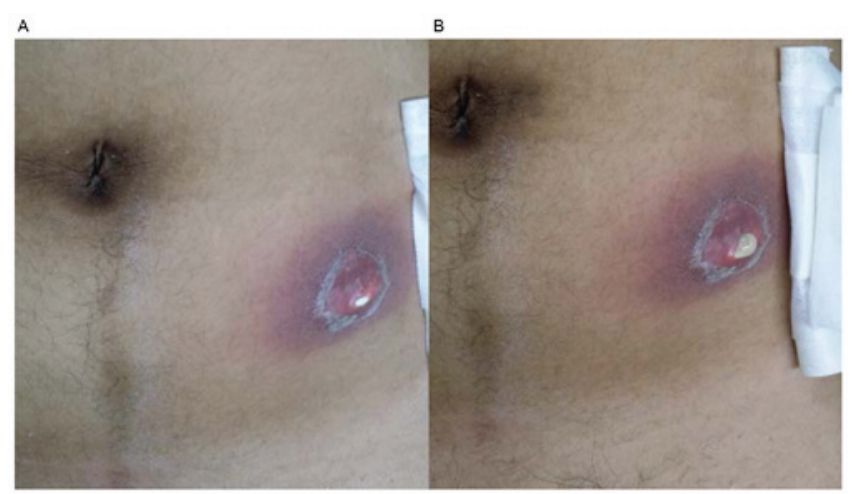

Figure 4. Case 10 presented with (A) distal catheter protruding out of the abdominal wall and (B) broken abdominal skin due to empyema.

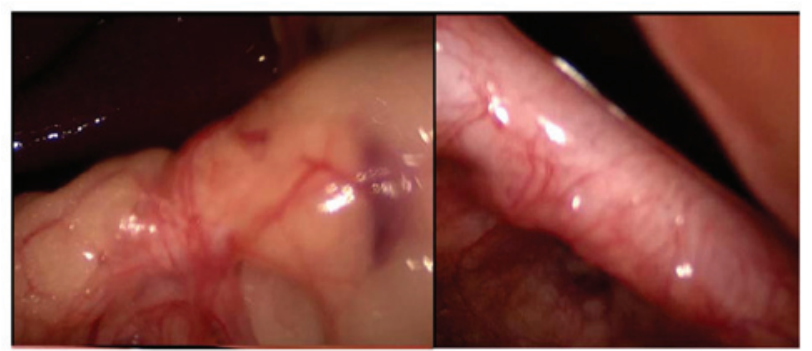

Figure 5. In Case 30, the distal catheter was engulfed, coiled and wrapped by the peritoneum and the omentum.

shunt-related infections or catheter malfunctions. No injuries occurred to the intra-abdominal organs. Physical examination, CT scan, gait test and MMSE were made every $6 \pm 1.8$ months following surgery. No laparoscopy-related complications were observed during the follow-ups. Abdominal digital radiography revealed that the shunt catheters had been placed within the subdiaphragmatic space (Fig. 6). 


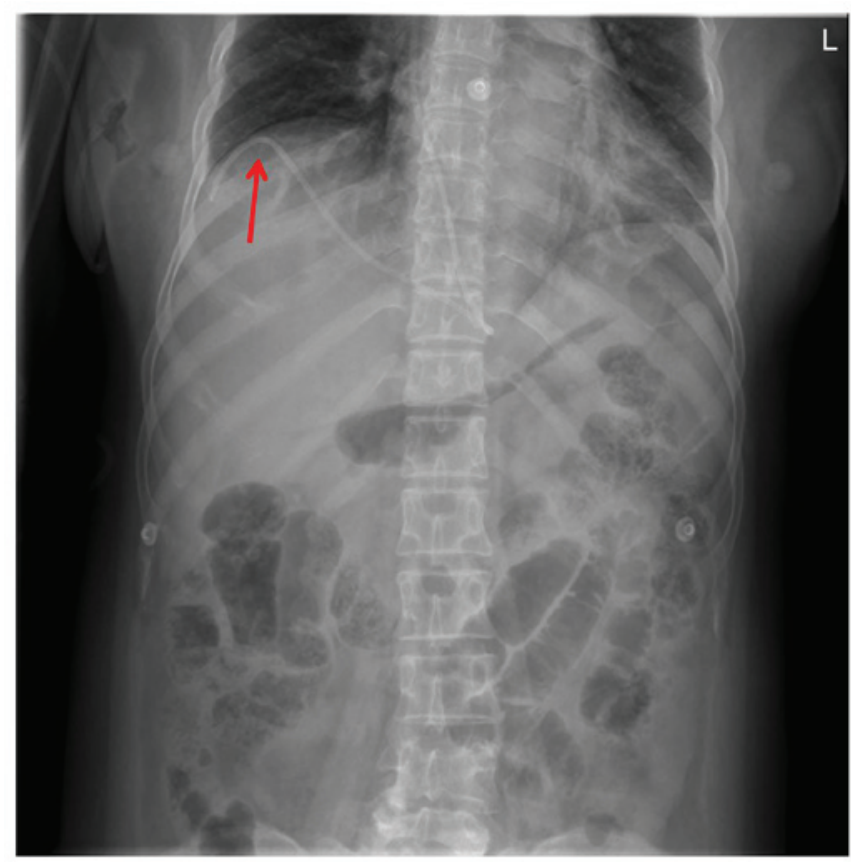

Figure 6. Shunt catheter within the subdiaphragmatic space (red arrow).

\section{Discussion}

VPS is a common procedure for the treatment of hydrocephalus, with a high complication rate of $5-47 \%$ (5). Distal mechanical malfunctions comprise $25-30 \%$ of all failures (10). Therefore, various techniques have been developed for placing the distal ends of the shunts, including mini-laparotomy, using a trocar to penetrate the abdominal wall layers and peritoneum and laparoscopy (11). The majority of these novel methods still involve positioning the VPS tube in the peritoneal or pelvic cavities. However, the positioning of the catheter may not be optimally placed in the preferred area, and the catheter may become wrapped or engulfed within the peritoneum and omentum (as in Case 10). The procedure does not actually prevent the malfunction of the shunt tube. The liver falciform ligament was selected in this novel procedure as a natural support for the catheter end due to its unique anatomic features (12). This position has no omental structures and placing the catheter in this area may prevent engulfment or coiling within the greater omentum (13), particularly in patients with shunt tube adjustments and a history of abdominal surgery.

Therefore, shunt placement techniques have become a focus of extensive research (9). However, disadvantages of the existing techniques remain and lead to difficult surgeries with extensive trauma. The present study demonstrated that, with the novel peritoneocentesis trocar, the peritoneal end of the VPS tube may be quickly and effectively placed within the subdiaphragmatic space. Additionally, the novel trocar facilitated a fast, convenient surgery that required an incision of only $0.5 \mathrm{~cm}$ (the trocar incision for the laparoscope) plus a $0.5-\mathrm{cm}$ incision (for the placement of the abdominal shunt tube) and smaller peritoneal and fascial openings. No surgery-related infections or catheter obstructions occurred in the patients who underwent this novel procedure.
However, placement of the peritoneal catheter may be difficult in certain cases, particularly in patients with a history of abdominal surgery or peritonitis and patients who have previously undergone failed attempts at VPS insertion (14). In these patients, the positioning of the catheter may not be optimal in the preferred area, and the majority of these patients present with peritoneal adhesions (7). The conditions of the abdomen may cause another adhesion or the malfunction of a new or revised shunt (as in Case 10). The revision of a failed distal catheter through a previous laparotomy incision may result in repeated retropulsion of the incision, hernia or adhesion (15). The use of laparoscopic surgeries for procedures to treat intra-abdominal pathologies has increased in popularity. However, these surgeries still have disadvantages and may be difficult surgeries to complete, with a high risk of extensive trauma.

In the majority of cases, shunt infections occur within 2 months of surgery, which suggests that the colonization of the shunt during placement has a crucial role in the cause of infection (16). Shunt surgeries were performed expeditiously in the present study with a mean surgery time of $\sim 48$ min as longer surgery times are considered to be a contributing factor to shunt infection $(17,18)$. Reducing the surgical time may markedly reduce the postoperative complication rate (19). In the current study, the duration of the entire VPS implantation ranged from 22 to $53 \mathrm{~min}$, and the mean surgery time was $32.6 \pm 5.6 \mathrm{~min}$. The duration of laparoscopy ranged from 6 to $18 \mathrm{~min}$, with a mean of $10.4 \pm 1.6 \mathrm{~min}$.

Other laparoscopic shunt tube placement strategies require longer surgery times and more abdominal trocar incisions (>3) for tube placement, which increases the surgical trauma (12). The technique used in the current study addresses these issues. The other primary advantage of the technique used in the present study is that smaller incisions [totaling only $1 \mathrm{~cm}(0.5+0.5 \mathrm{~cm})$ ] are utilized. The peritoneal and fascial openings are smaller. Less surgically induced trauma leads to a faster postoperative recovery and fewer secondary peritoneal adhesions $(20,21)$. The distal shunt may be placed in the desired position under laparoscopic supervision. Appropriate placement of the peritoneal catheter is confirmed under direct visualization, and its patency is ensured by observing the free flow of cerebral spinal fluid through its distal end.

Distal shunt migration is an infrequent complication, particularly in obese patients (as in Case 30), and the cause of this complication remains unknown. The potential mechanisms include head movement and positive intra-abdominal pressure. However, these movements and pressure are unlikely to transmit to a fine catheter tube (22-24). Nagasaka et al (25) reported that moving from the supine position to the standing position causes the abdominal subcutaneous fat pad to slide down, and the shifted subcutaneous fat pad pulls the catheter out of the peritoneal cavity. Furthermore, anchoring, for example, with a fibrous encasement, prevents the catheter from returning into the peritoneal cavity (25). The thick fat pad of obese patients also causes difficulty in the placement of the distal catheter. In the present study, the catheter was introduced using the xiphoid process. This position has little subcutaneous fat; thus, may be an ideal position far from the abdominal subcutaneous fat pad. The abdominal end of the 
shunt tube was placed into the abdominal cavity from the area below the xiphoid process, which is far from the fatty pad of the abdominal wall. In this manner, the difficulty of a surgery involving the abdominal fat pad was avoided, along with the potential complication of the abdominal end of the shunt tube poking up from the level of the abdominal skin surface due to the relative displacement of the abdominal fat pad.

In conclusion, the novel trocar technique demonstrated in the present study is easy to perform and minimally invasive. Under laparoscopic supervision, the catheter may be advanced to the desired location. Although the number of cases in the present study was small, the rationale is convincing. The novel approach used in the current study may significantly reduce the risk of malfunction complications in patients with abdominal abnormalities and particularly in obese patients and patients with abdominal adhesions or shunt revisions. A larger multicenter study is required to more comprehensively investigate these issues (26). Therefore, a larger prospective randomized multicenter clinical study is required to increase the statistical power.

\section{Acknowledgements}

The present study was supported by the Technological Innovation Foundation of Jilin Province (grant no. 2013S016).

\section{References}

1. Kasuya H, Shimizu $T$ and Kagawa $M$ : The effect of continuous drainage of cerebrospinal fluid in patients with subarachnoid hemorrhage: A retrospective analysis of 108 patients. Neurosurgery 28: 56-59, 1991.

2. Park YS, Park IS, Park KB, Lee CH, Hwang SH and Han JW: Laparotomy versus laparoscopic placement of distal catheter in ventriculoperitoneal shunt procedure. J Korean Neurosurg Soc 48: 325-329, 2010.

3. Tepetes K, Tzovaras G, Paterakis K, Spyridakis M, Xautouras N and Hatzitheofilou C: One trocar laparoscopic placement of peritoneal shunt for hydrocephalus: A simplified technique. Clin Neurol Neurosurg 108: 580-582, 2006.

4. Sotelo J, Izurieta M and Arriada N: Treatment of hydrocephalus in adults by placement of an open ventricular shunt. J Neurosurg 94: 873-879, 2001.

5. Brunori A, Massari A, Macarone-Palmieri R, Benini B and Chiappetta F: Minimally invasive treatment of giant CSF pseudocyst complicating ventriculoperitoneal shunt. Minim Invasive Neurosurg 41: 38-39, 1998.

6. Kusano T, Miyazato H, Shimoji H, Hirayasu S, Isa T, Shiraishi M, Muto Y and Furukawa M: Revision of ventriculo-peritoneal shunt under laparoscopic guidance in patients with hydrocephalus. Surg Laparosc Endosc 8: 474-476, 1998.

7. Roth J, Sagie B, Szold A and Elran H: Laparoscopic versus non-laparoscopic-assisted ventriculoperitoneal shunt placement in adults. A retrospective analysis. Surg Neurol 68: 177-184, 2007.
8. Sotelo J, Arriada N and López MA: Ventriculoperitoneal shunt of continuous flow vs valvular shunt for treatment of hydrocephalus in adults. Surg Neurol 63: 197-203, 2005.

9. Wang GM, Fu SL, Ge PF, Fan WH, Li GM, Meng FK and Luo YN: Use of a new type of trocar for the surgical treatment of hydrocephalus: A simple and effective technique. J Int Med Res 39: 766-771, 2011.

10. Kestle J, Drake J, Milner R, Sainte-Rose C, Cinalli G, Boop F, Piatt J, Haines S, Schiff S, Cochrane D, et al: Long-term follow-up data from the Shunt Design Trial. Pediatr Neurosurg 33: 230-236, 2000.

11. Svoboda SM, Park H, Naff N, Dorai Z, Williams MA and Youssef Y: Preventing Distal Catheter Obstruction in Laparoscopic Ventriculoperitoneal Shunt Placement in Adults: The 'Falciform Technique'. J Laparoendosc Adv Surg Tech A 25: 642-645, 2015.

12. Shao Y, Li M, Sun JL, Wang P, Li XK, Zhang QL and Zhang L: A laparoscopic approach to ventriculoperitoneal shunt placement with a novel fixation method for distal shunt catheter in the treatment of hydrocephalus. Minim Invasive Neurosurg 54: 44-47, 2011.

13. Svoboda SM, Park H, Naff N, Dorai Z, Williams MA and Youssef Y: Preventing Distal Catheter Obstruction in Laparoscopic Ventriculoperitoneal Shunt Placement in Adults: The 'Falciform Technique' J Laparoendosc Adv Surg Tech A 25: 642-645, 2015.

14. Schievink WI, Wharen RE Jr, Reimer R, Pettit PD, Seiler JC and Shine TS: Laparoscopic placement of ventriculoperitoneal shunts: Preliminary report. Mayo Clin Proc 68: 1064-1066, 1993.

15. Morrison JF, Sung KE, Bergman AM, Rosenblatt MS and Arle JE: A novel solution to reduce the complications of distal shunt catheter displacement associated with obesity. J Neurosurg 113: 1314-1316, 2010.

16. Faillace WJ: A no-touch technique protocol to diminish cerebrospinal fluid shunt infection. Surg Neurol 43: 344-350, 1995.

17. Kestle JR, Hoffman HJ, Soloniuk D, Humphreys RP, Drake JM and Hendrick EB: A concerted effort to prevent shunt infection. Childs Nerv Syst 9: 163-165, 1993

18. Kontny U, Höfling B, Gutjahr P, Voth D, Schwarz M and Schmitt HJ: CSF shunt infections in children. Infection 21: 89-92, 1993.

19. Bronitsky C, Payne RJ, Stuckey S and Wilkins D: A comparison of laparoscopically assisted vaginal hysterectomy vs traditional total abdominal and vaginal hysterectomies. J Gynecol Surg 9: 219-225, 1993

20. Gutt CN, Oniu T, Schemmer P, Mehrabi A and Büchler MW: Fewer adhesions induced by laparoscopic surgery? Surg Endosc 18: 898-906, 2004.

21. Novitsky YW, Litwin DE and Callery MP: The net immunologic advantage of laparoscopic surgery. Surg Endosc 18: 1411-1419, 2004.

22. Kim KJ, Wang KC and Cho BK: Proximal migration and subcutaneous coiling of a peritoneal catheter: Report of two cases. Childs Nerv Syst 11: 428-431, 1995.

23. Pang D and Wilberger JE Jr: Upward migration of peritoneal tubing. Surg Neurol 14: 363-364, 1980.

24. Scott M, Wycis HT, Murtagh F and Reyes V: Observations on ventricular and lumbar subarachnoid peritoneal shunts in hydrocephalus in infants. J Neurosurg 12: 165-175, 1955.

25. Nagasaka $T$, Inao $S$, Ikeda $H$, Tsugeno $M$ and Okamoto $T$ : Subcutaneous migration of distal ventriculoperitoneal shunt catheter caused by abdominal fat pad shift-three case reports. Neurol Med Chir (Tokyo) 50: 80-82, 2010.

26. Kehler U, Klöhn A, Heese O and Gliemroth J: Hydrocephalus therapy: Reduction of shunt occlusions using a peel-away sheath. Clin Neurol Neurosurg 105: 253-255, 2003. 